\title{
MANO INVISIBLE, CLÁUSUlas LOCKEANAS Y JUSTICIA PRIVADA: EMERGENCIA Y JUSTIFICACIÓN DEL ESTADO EN ANARQUÍA, ESTADO Y UTOPÍA*
}

\author{
Invisible-Hand, Lockean Provisos and Private Justice: \\ Emergence and State's Legitimacy in Anarchy, State and Utopia
}

\section{FELIPE SCHWEMBER AUGIER}

Universidad Adolfo Ibáñez

\begin{abstract}
RESUMEN
El presente trabajo analiza el argumento ofrecido por Nozick en favor de la licitud del Estado. Se sostendrá que, bien entendido, este argumento hace frente a dos dificultades diferentes: una descriptiva (el surgimiento inocuo e inintencionado del Estado) y otra de iure (la legitimidad del Estado). La primera es resuelta por Nozick a través de una explicación de mano invisible, la segunda por medio del denominado principio de compensación. Se intentará demostrar que este principio es compatible con la filosofía política de Locke y, por tanto, con el liberalismo de inspiración lockeana.
\end{abstract}

Palabras clave: Nozick, libertarianismo, anarquismo, orden espontáneo.

\begin{abstract}
This work analyses the argument provided by Nozick in support of the State's legitimacy. It will be held that, in fact, this argument deals with two different difficulties: a descriptive one (the harmless and unintended emergence of the State) and another de jure (the legitimacy of the State). The first one is resolved by Nozick via the invisible-hand explanation, and the second one via so-called principle of compensation. I will attempt to demonstrate that this principle is consistent with Locke's political philosophy and, therefore, with lockean libertarianism.
\end{abstract}

Key words: Nozick, libertarianism, anarchism, spontaneous order.

El presente trabajo fue redactado como parte de un proyecto de investigación financiado por Fondecyt (Chile) (Proyecto № 11130057). Agradezco al profesor Miguel González Vallejos por sus comentarios y sugerencias. Agradezco también a los evaluadores anónimos de la Revista de Ciencia Política de la Pontificia Universidad Católica de Chile, cuyas observaciones y sugerencias ayudaron a mejorar sustancialmente este trabajo. 


\section{INTRODUCCIÓN}

En la primera parte de Anarquía, Estado y utopía, ${ }^{1}$ Nozick ofrece un original e improbable argumento para demostrar la licitud del Estado contra las objeciones que al respecto levanta una clase particular de anarquistas denominados "anarquistas individualistas". Este argumento, que ha sido muchísimo menos estudiado que la teoría de los títulos posesorios presentada en la segunda parte de la obra, ha sido objeto de diversas críticas y, por regla general, ha sido desechado de modo sistemático por la literatura especializada. ${ }^{2}$ En el presente trabajo examinaremos los tres ejes principales de dicho argumento con el fin de formular un juicio acerca de su viabilidad general y de su concordancia con los presupuestos de un estado de naturaleza lockeano. Para ello nos detendremos, primero, en la explicación de mano invisible ofrecida por Nozick para determinar en qué sentido ella puede ser considerada como parte de un argumento hipotético en favor de la licitud del Estado. Se sostendrá que la explicación de mano invisible por sí misma no aporta premisas normativas al argumento y que, por el contrario, tiene únicamente por cometido solventar un problema descriptivo: proporcionar un relato acerca del posible surgimiento inintencionado e inocuo de un Estado (ultramínimo) a partir de un estado inicial lockeano. Se sostendrá que las posibilidades normativas de la explicación de mano invisible (y que permiten que dicha explicación pueda llegar a contar como parte de un argumento) radican en los presupuestos morales de los que dicha explicación parte, y que están contenidos en el estado de naturaleza lockeano que sirve de trasfondo general a la argumentación de Nozick. De ahí que, contra lo que se suele entender, la explicación de mano invisible ofrecida en ASU no pueda contar, en rigor, como el argumento de Nozick a favor del Estado, sino tan solo como una parte -y tal vez la menos importante- del mismo.

A continuación se examinarán los otros dos ejes del argumento: el derecho a castigar y el principio de compensación. Luego de revisar algunas de las dificultades que entraña el derecho natural a castigar, se argüirá que la imposibilidad de dirimir entre diferentes procedimientos en estado de naturaleza no ofrece al anarquista individualista una objeción que pueda utilizar contra Nozick sin ver comprometida su propia posición. En seguida se examinará el papel que desempeña el principio de compensación. Se sostendrá que es por medio de este principio que Nozick intenta resolver, en definitiva, el problema normativo que más le interesa en su discusión con el anarquista individualista: la licitud del surgimiento del Estado. Por eso se sostendrá que es el principio de compensación el que soporta, en último término, el peso de la argumentación. Se argüirá además que, contra lo que se suele afirmar, este principio no es contrario al espíritu general del lockeanismo y que, por el contrario, este necesita recurrir a él, especialmente al momento de intentar justificar la propiedad privada.

En adelante abreviado por sus iniciales en inglés, " $A S U$ ".

Entre los escasos artículos o monografías que tratan todo o parte de este argumento se encuentran: Barnett (1977); Holmes (1981); Paul (1981); Paul Wolff (1981); Mack (1981); Young (1986); Wolff (1991); Rothbard (1995); Miller (2002); Roark (2007); Mack (2011) y Gaus (2011). 
En virtud de todo lo anterior se concluirá que, dentro de los términos del propio libertarismo lockeano, el argumento de ASU a favor del Estado resulta mucho más sólido y convincente de lo que sus detractores libertarios y anarquistas han estado dispuestos comúnmente a admitir.

\section{EL ESTADO DE NATURALEZA Y EL “PREDICAMENTO LOCKEANO”}

El blanco de la argumentación de la primera parte de ASU es el así llamado "anarquista individualista" (1988: 61). Las objeciones levantadas por dicho anarquista contra la inevitable pretensión del Estado de monopolizar el uso de la fuerza y de erradicar el ejercicio privado de la justicia solo cobran plausibilidad bajo los presupuestos de un estado de naturaleza lockeano. ${ }^{3}$ Como se sabe, dicho estado no solo no es un espacio normativamente libre (i.e., un espacio carente de reglas), sino que, además, no es un estado de depredación mutua. En él existe, por el contrario, un amplio margen para la cooperación recíproca. La conjunción de estos factores explica que en dicho universo el aseguramiento de los derechos naturales mediante el ejercicio privado de la justicia no desemboque necesariamente en un estado de guerra. De hecho, bajo la constelación descrita es la instauración de un Estado y la proscripción del ejercicio de la justicia privada lo que resulta problemático, pues si todos los individuos tienen igualmente derecho para infligir castigo y si, según los mismos presupuestos de Locke, el ejercicio de tal derecho puede producir inconvenientes pero no desemboca de suyo en un estado de guerra, entonces ¿con qué autoridad puede alguien prohibirme el legítimo ejercicio de mi derecho a ejecutar la ley natural? Dado que la existencia del Estado es de suyo incompatible con la conservación por parte de los individuos del derecho natural a hacerse justicia por sí mismos y dado, además, que de este último derecho depende la efectividad de todos los otros derechos naturales, entonces la existencia del Estado resulta incompatible in toto con la ley natural y con la asunción de que los individuos son titulares de derechos naturales. Esta incompatibilidad es la que ha dado pábulo al así llamado "predicamento lockeano" (Wolff, 1991: 38-40), y por ella el problema de la legitimidad del Estado queda sujeto al problema de la legitimidad de la proscripción de la justicia privada.

Dado que comparte con los anarquistas el diagnóstico del problema, al momento de fijar los términos dentro de los cuales se desenvuelve la discusión, Nozick lo hace de la siguiente manera:

3 En consecuencia, el argumento de Nozick a favor del Estado no pretende servir de refutación de todas las formas de anarquismo, sino solo del anarquismo individualista derivado de la tradición lockeana con la que Nozick comparte varios presupuestos. Esta forma de anarquismo liberal -llamado normalmente "anarcocapitalismo" - constituye una corriente muy minoritaria dentro de la tradición anarquista. Las otras formas de anarquismo -que podríamos denominar genéricamente "anticapitalistas"- parten de otros presupuestos y quedan, por tanto, fuera de los términos de la controversia que existe entre Nozick y los anarquistas individualistas. Para una visión general del anarquismo clásico, cf. Marshall, 2008: 191-427. Como bien dice Marshall, pocos anarquistas admitirían a los anarcocapitalistas dentro de sus filas (2008: 565). Aquí, no obstante, podemos pasar por alto ese problema. 
Cuando un grupo de personas se constituye en Estado, comienza a castigar y prohíbe a otros hacer lo mismo, ¿hay algún derecho que estos últimos violarían [en caso de hacer lo mismo que los primeros] y que aquellos que constituyen el Estado no violaran? ¿Basados en qué derecho, en consecuencia, pueden el Estado y sus funcionarios reclamar un derecho (un privilegio) exclusivo para imponer y aplicar este monopolio? (1988: 62).

Nozick cree poder resolver el problema de la proscripción de la justicia privada combinando una explicación de mano invisible con un principio político-moral que denomina principio de compensación. Ambos le permiten idear una narración que relata la génesis ideal del Estado y que tiene por finalidad mostrar no que algún Estado particular es legítimo, sino, más bien, mostrar que ex hypothesi, podría haber un Estado cuyo surgimiento no entrañara la violación de los derechos y libertades naturales de aquellos que quedan bajo su autoridad. La narración -que consistirá por tanto en la exposición de las condiciones ideales bajo las cuales dicho surgimiento es inocuo- tiene un alcance bastante modesto: solo pretende mostrar que alguna vez, bajo ciertas condiciones determinadas, podría ocurrir que el surgimiento del Estado no entrañara una violación de los derechos de los individuos que quedan bajo su autoridad. No obstante, por modesto que sea, de ser dicha hipótesis correcta, la incompatibilidad entre los derechos individuales y la existencia del Estado se mostraría como meramente accidental y no necesaria como quieren los anarquistas individualistas. Por ello, aun cuando no avale ni sirva a los Estados existentes hinc et nunc, sino solamente a algún Estado posible, la narración de Nozick tiene el potencial de refutar la tesis central del anarquismo individualista.

\section{LA GÉNESIS IDEAL DEL ESTADO (MÍNIMO)}

La narración de Nozick a favor del Estado parte con una explicación de mano invisible, esto es, con una explicación que pretende ilustrar cómo a partir de un conjunto de acciones voluntarias y no concertadas de diferentes individuos surge de modo inintencionado el Estado o, más exactamente, lo que él llama el Estado ultramínimo. El paso ulterior al Estado mínimo se justifica apelando al así llamado principio de compensación. Este proceso tiene varias fases, que pueden resumirse del siguiente modo:

1) Asociaciones de protección mutua. En un estado de naturaleza lockeano "un individuo puede, por sí mismo, imponer sus derechos, defenderse, exigir compensación y castigar" (Nozick, 1988: 24-25). Pero los individuos pueden, igualmente, asociarse para protegerse unos a otros. Estas asociaciones de protección mutua brindan seguridad y mayor efectividad en la defensa y reivindicación de los propios derechos, pero adolecen de ciertos inconvenientes: el que todos deban por igual acudir al llamado que realice alguno de sus miembros y cumplir las tareas defensivas y de castigo que se les encomienden termina siendo ineficiente. El mejor modo de remediar esta ineficiencia es encomendar dichas tareas a algunos miembros del grupo mientras los otros miembros realizan aquellas labores para las cuales tienen alguna ventaja comparativa. El problema, en consecuencia, de la ineficiencia del sistema de las 
asociaciones de protección mutua "puede ser manejada de la manera usual: por división del trabajo e intercambio" (Nozick, 1988: 26).

2) Agencias de protección. En la medida en que las labores en las asociaciones de protección mutua se especializan, las relaciones entre los individuos que la conforman devienen puramente contractuales: unos individuos ofrecen servicios de protección a otros que pagan por ello una tarifa. Entonces se forman las agencias de protección.

3) Agencia de protección dominante. Aparecen diversas agencias de protección que compiten entre sí ofreciendo cobertura, pólizas o tarifas diferentes. Tales agencias entran eventualmente en conflicto por las diferencias entre ellas a la hora de juzgar las controversias suscitadas entre sus respectivos clientes. Entonces puede ocurrir, dice Nozick, lo siguiente: 1) se produce una lucha entre dos agencias. Una de ellas invariablemente gana, de suerte que los clientes de la agencia perdedora se pasan a la agencia ganadora; 2) una agencia vence por regla general en una determinada área geográfica, mientras la otra lo hace en otra. Los individuos, en consecuencia, contratan a la agencia que tiene el predominio del lugar donde viven o se mudan allí donde la tiene aquella con la que han contratado. Esto tendería a definir ciertas "fronteras" entre una y otra agencia, semejantes y tan conflictivas como los que existen entre los Estados; 3) las dos agencias luchan constantemente sin que haya resultados decisivos a favor de una $u$ otra. Como estas luchas resultan ruinosas para ambas agencias, se acuerda un sistema de arbitraje imparcial que ambas acuerdan respetar, que configura lo que podría considerarse una suerte de derecho interestatal. Así, de las asociaciones de protección mutua hemos llegado a la agencia de protección dominante: en una determinada área geográfica existe una agencia de protección dominante cuyas características comienzan, al menos en cierto grado, a asemejarse a un Estado.

4) Los independientes. Una de las originalmente numerosas agencias ha logrado limpiamente desplazar a las agencias competidoras y cuenta, por ello, virtualmente con el monopolio del uso de la fuerza en un determinado territorio. Pero solo "virtualmente", pues aún pueden quedar individuos -los independientes- que prefieran ejercer por sí mismos sus derechos a obtener reparación e infligir castigo. En este caso "el territorio cubierto por la asociación de protección semejaría, entonces, una rebanada de queso suizo, con linderos internos y externos" (Nozick, 1988: 63).

5) Prohibición a los independientes y Estado ultramínimo. En un universo lockeano, ninguna agencia está autorizada para impedir arbitrariamente al independiente el ejercicio de su derecho a castigar ni forzarle a contratar protección ${ }^{4}$. Sin embargo, llegado a la fase descrita en 4), la agencia de protección dominante podría anunciar que se reservará el derecho de juzgar los procedimientos de administración de justicia que se vaya a aplicar a sus clientes. En caso de que la agencia juzgue que el procedimiento empleado

4 Como aclara Nozick: “[n]uestro relato anterior supone que cada una de las agencias intenta de buena fe actuar dentro de los límites del derecho natural en el sentido en que Locke lo entiende” (1988: 30). 
por el independiente en contra de su cliente es desconfiable e injusto, prohibirá se le aplique a su cliente o, en su defecto, procederá a castigar al independiente que lo haga. Tal prohibición descansa en el derecho natural al debido proceso de los clientes. La prohibición dirigida al independiente que emplea un procedimiento desconfiable o injusto exige se determine qué tipos de acciones ponen en un riesgo intolerable a los demás. De otro modo la prohibición sería arbitraria. Por eso Nozick desarrolla en este punto de la narración una teoría del riesgo y de la compensación que aquí no podemos abordar. Baste decir que la idea general de Nozick es que un individuo tiene derecho a prohibir a otro una acción riesgosa a cambio de una compensación, de suerte que, conforme a ese mismo principio general, la agencia tiene derecho a prohibir al independiente el ejercicio de su derecho al castigo sobre sus clientes a cambio de una compensación. La compensación, en el caso del independiente, será el ofrecimiento de cobertura gratuita. De todos modos, por ahora solo interesa subrayar que la prohibición impuesta al independiente otorga de facto a la agencia el monopolio de la fuerza en un territorio determinado. Ese monopolio consuma de hecho el paso al Estado ultramínimo.

6) Compensación a los independientes y Estado mínimo. El tránsito del Estado ultramínimo al Estado mínimo (i.e., del Estado que ofrece protección solo a los que pagan por ella al Estado que ofrece protección a todos) tiene lugar por la aplicación del principio de compensación. Puesto que la prohibición impuesta al independiente lesiona sus derechos, los individuos en cuyo favor se ha formulado dicha prohibición deben ofrecer una compensación suficiente. La forma más económica de compensación que la agencia puede ofrecer a los independientes es proporcionarles protección gratuita. La extensión gratuita del servicio a los independientes se reflejaría, naturalmente, en la tarifa o en el precio de la póliza que la agencia cobra a sus propios clientes que son, en definitiva, los que soportan el costo que significa la compensación. Esta extensión -que, subraya Nozick, obedece a razones compensatorias y no distributivas- da lugar, finalmente, al Estado mínimo, a juicio de Nozick, el Estado más extenso que se puede justificar sin infringir o violar los derechos de las personas (1988: 118).

Ahora bien, puesto que la explicación que intenta construir Nozick debe mostrar, no cómo de hecho puede surgir de modo inintencionado el Estado a partir de las acciones racionales de los individuos en un universo lockeano, sino cómo podría surgir un Estado sin conculcar los derechos de nadie, el punto crítico de la explicación de Nozick se encuentra en el tránsito de la Agencia de protección dominante al Estado ultramínimo, pues allí la narración debe salvar el abismo que se abre entre una cuestión de hecho (el crecimiento inintencionado de la agencia hasta convertirse en dominante) y una cuestión de derecho (la licitud de la prohibición impuesta al independiente de hacerse justicia por su propia mano a cambio de una compensación). Este abismo -que en la narración no se cierra en virtud de un proceso inintencionado- intenta Nozick salvarlo apelando al principio de compensación y no mediante la explicación de mano invisible. La explicación de mano invisible permite, en el mejor de los casos, dar cuenta del monopolio de facto que alcanza 
la agencia de protección, no justificar el monopolio de iure que detenta (o al menos reclama) cualquier Estado (Nozick, 1988: 122). En consecuencia, desde el punto de vista normativo, es fundamentalmente el principio de compensación y no la explicación de mano invisible el que soporta el peso de la argumentación ideada por Nozick. Esto no significa, sin embargo, que el papel de la explicación de mano invisible en la narración de Nozick de la génesis ideal del Estado sea superfluo.

\section{EXPLICACIONES FUNDAMENTALES, POTENCIALES, CONTRATO Y CONSENTIMIENTO}

Puesto que el argumento que Nozick necesita en favor del Estado es un argumento contrafáctico sujeto a ciertas condiciones normativas ¿por qué no ha recurrido Nozick a la ficción de un contrato social?

Nozick ofrece una importante razón en favor de las explicaciones de mano invisible cuando afirma que las mismas constituyen un tipo de explicación privilegiada por su capacidad de iluminar todo un campo sin recurrir a las nociones constitutivas de ese mismo campo. Dicho sucintamente, "[l]as explicaciones de mano invisible minimizan el uso de las nociones que constituyen el fenómeno por explicar" y por eso Nozick las denomina explicaciones fundamentales (1988: 32). Por consiguiente, para el caso que nos ocupa, puede entenderse que la ventaja de una explicación de mano invisible por sobre una "explicación" contractualista radica en que la primera introduce en el discurso las categorías o instituciones políticas (como por ejemplo el Estado) como propiedades emergentes de procesos eminentemente no políticos (Nozick 1988: 19). Dicho de otro modo, la explicación de mano invisible constituye una explicación fundamental del campo político. La explicación contractualista no. ${ }^{5}$

Pero no se trata tan solo de que el contractualismo no pueda servir como explicación fundamental. El contractualismo adolece de un problema adicional: tampoco puede -a diferencia de la explicación ideada por Nozick- servir como explicación potencial. Nozick afirma, siguiendo a Hempel, que la explicación potencial es aquella que "sería la explicación correcta si todas las cosas mencionadas en ellas fueran ciertas y operaran" (1988: 20). ${ }^{6}$ La explicación potencial, por tanto, tiene un carácter hipotético, pero -como queda claro a medida que se avanza en la narración- para Nozick lo tiene no solo en el sentido de que parta de leyes establecidas tentativamente sino además, al menos para la argumentación ofrecida en la primera parte de $A S U$, en el sentido de que puede partir de ciertas premisas normativas que procuran dar con las condiciones bajo las cuales un cierto resultado $X$ es lícito. Este uso, que tiende a nivelar las explicaciones potenciales con las historias hipotéticas, va, ciertamente, más allá de la caracterización que Hempel

Una explicación potencial es aquella en que los enunciados legaliformes que se ofrecen para dar cuenta del fenómeno que se quiere explicar cumplen con todos los requisitos de una explicación nomológico-deductiva verdadera, con excepción de la exigencia de verdad de esos mismos enunciados. Cf. Hempel, 2005: 325 y ss. 
da de este tipo de explicaciones ${ }^{7}$ y ha suscitado críticas por la confusión que importa entre una explicación y una justificación (Paul Wolff, 1982: 80). Es claro, sin embargo, que lo que necesita Nozick es un argumento hipotético en favor de la licitud del Estado, no una explicación acerca de su génesis histórica. Por eso, cuando dice que la suya es una "explicación fundamental potencial", ello no debe tomarse en el sentido estricto que le da Hempel, sino en un sentido más general.

Como fuere, Nozick parece coincidir con la opinión de los detractores del contractualismo en que para resultar vinculante el consentimiento deber ser, en último término, real y no meramente hipotético: ${ }^{8}$

Si la hipotética historia justa presupone que cada persona consienta en la estructura institucional y en cualquier limitación de sus derechos [...] entonces, si alguna persona real no consintiera, habría que considerar injusta la estructura institucional. Similarmente, hay que tener por injusta la estructura institucional si la hipotética historia justa presupone el consentimiento de algunas persona que no consintieron y algunas, ahora, no aprobarían a aquellas que lo hubieran hecho (1988: 282-283).

Aunque puede discutirse la pertinencia de esa objeción, el hecho es que al exigir un consentimiento real y no meramente hipotético, el contrato se vuelve inútil como explicación potencial en particular y como herramienta metódica en general: el veto de un anarquista que se opone por principio a todo acuerdo celebrado con vistas a la instauración de un Estado será suficiente para frustrar de modo sistemático su constitución.

Estas dificultades a que tiene que hacer frente el contractualismo permiten entrever qué es lo que Nozick pretende con la explicación de mano invisible: eludir (más que refutar) las objeciones del anarquista y, más precisamente, prescindir de su consentimiento a la hora de legitimar la existencia del Estado. Si las acciones voluntarias, lícitas y no concertadas de todos los individuos pueden conducir al surgimiento del Estado ¿qué objeción podría levantar legítimamente el anarquista al respecto? ¿Y qué puede tener que ver en ello su consentimiento? El argumento de mano invisible no pretende -como el argumento contractualista- argüir en favor de la necesidad de instaurar un Estado sino, más bien, argüir en favor de la posibilidad de que pudiera surgir inintencionadamente sin conculcar los derechos de nadie.

Estas dificultades permiten también entender por qué la explicación de mano invisible y todo el resto de la narración de Nozick sí funciona como explicación potencial y el contractualismo no: tarde o temprano el contractualismo requiere del consentimiento efectivo para justificar la autoridad del Estado y ese consentimiento no puede sustituirse por ninguna ficción metódica. La explicación de mano invisible de Nozick, en cambio, no requiere del consentimiento de nadie en orden a la instauración del Estado, requiere "tan solo" que el surgimiento inintencionado del

7 Hempel exige que el explanans tenga contenido empírico esto es, sea empíricamente contrastable. Pero ¿en
qué sentido puede ser contrastable una narración acerca de la génesis ideal del Estado?

$8 \quad$ Cf., por ejemplo, Hume, 2006: 105 y Dworkin, 1984: 235. 
Estado pudiere tener lugar alguna vez de forma inocua. De ahí que la explicación de Nozick pueda justificar un Estado posible mientras que la explicación contractualista solo Estados reales.

\section{EXPLICACIONES DE MANO INVISIBLE Y JUSTIFICACIÓN DEL ESTADO}

Después de leer la larga (e intrincada) narración del surgimiento inintencionado del Estado ultramínimo por medio de un proceso de mano invisible es inevitable preguntarse en qué contribuye esta explicación a la justificación del Estado, si es que contribuye en algo a ello. Por de pronto, uno podría preguntarse por qué debiera seguir considerándose como tal a una explicación que renuncia de antemano a toda verosimilitud histórica. ${ }^{9}$

Pero como se ha adelantado, la explicación que ofrece Nozick no pretende narrar la génesis de ningún Estado particular y, por tanto, no pretende verosimilitud histórica. Más bien, como afirma Nozick, de lo que se trata es de ofrecer una explicación acerca de cómo surgiría el Estado en un estado de naturaleza (lockeano) "aún si ningún Estado real hubiera jamás surgido de esa manera" (1988: 20). En consecuencia, de lo que se trata en la explicación de mano invisible es dar con el conjunto de condiciones bajo las cuales el surgimiento del Estado como consecuencia de las acciones no concertadas de los individuos resultaría lícito. Por tal motivo, la explicación de mano invisible que ofrece Nozick se mantiene en pie no por su fidelidad histórica, sino por sus posibilidades normativas: ella expresa las condiciones bajo las cuales el surgimiento del Estado sería lícito. De este modo la explicación deviene, en realidad, parte de un argumento más amplio a favor del Estado.

Sin embargo, si, como el mismo Nozick advierte, las explicaciones de mano invisible son descriptivas y no normativas (Nozick, 1994: 314) ¿cómo es posible o en qué sentido puede considerarse que la explicación de mano invisible ofrecida en la primera parte de ASU como parte de un argumento en favor de algo? La advertencia de Nozick nos debiera alertar acerca de cómo debe interpretarse dicha explicación: si la explicación tiene fuerza normativa (y deviene por ello en argumento en favor de algo), la tendrá no en tanto que explicación de mano invisible, sino en tanto se combina o vincula con alguna premisa o supuesto que le dota de fuerza normativa. Uno de los problemas, por consiguiente, que suscita el argumento de mano invisible en favor del Estado es el de determinar de dónde proviene su fuerza normativa.

Para dilucidar este problema es necesario, primero, detenerse a considerar la naturaleza así como los diferentes tipos de explicaciones de mano invisible. Por de pronto, Nozick distingue dos tipos de proceso que se corresponden a dos tipos de explicación de mano invisible: los procesos de filtro y los procesos de equilibrio.

9 Rothbard, por ejemplo, insiste en este punto: “importa mucho comprobar si la ingeniosa construcción lógica de nuestro autor [i.e., Nozick] está respaldada por la realidad histórica, es decir, si todos los Estados, o al menos la mayoría de ellos, han surgido de hecho al modo nozickiano" (1995: 313). 
Podemos mencionar aquí dos tipos de procesos de mano invisible por los cuales se puede producir una pauta $P$ : procesos de filtración y procesos de equilibrio. Mediante el proceso de filtración únicamente pueden pasar cosas que satisfacen $P$, porque los procesos o estructuras eliminan todos los no $P$. En el proceso de equilibrio cada parte componente responde o se ajusta a las condiciones "locales", cambiando con cada ajuste, el ambiente local de otros componentes cercanos, de tal forma que la suma de escarceos de los ajustes locales constituye o realiza $P$ (Nozick, 1988: 34).

Estos dos tipos de procesos que distingue Nozick vienen a coincidir con los dos tipos de explicación de mano invisible que distingue Edna Ullmann-Margalit: agregativos y funcionales-evolutivos (Ullmann-Margalit, 1978). Las explicaciones del primer tipo dan cuenta no solo de cómo una práctica o institución ha de hecho surgido sino, también, por qué se mantiene o subsiste (Ullmann-Margalit, 1978: 275 y ss.). El ejemplo más recurrente de este tipo de explicación es el sistema de precios en un mercado libre. Las segundas, en cambio, explican la presencia constante de una determinada función en un sistema. ${ }^{10}$ Los procesos de filtración a que se refiere Nozick corresponden, fundamentalmente, a esta última categoría indicada por UllmannMargalit, y probablemente el mejor ejemplo para ilustrarla es la adaptación de los organismos biológicos, pues el filtro a partir del cual opera la selección natural es la adaptabilidad: todo aquello que no contribuye a la adaptabilidad en un organismo carece de función y, por ello desaparece, bien porque se atrofia, bien porque al convertirse en un lastre provoca la desaparición del organismo mismo en el que existe. Sería posible entender que, aplicada a las ciencias sociales, las explicaciones funcionales-evolutivas de mano invisible tienen una carga normativa o constituyen por derecho propio un argumento en favor de alguna práctica o institución: aquellas prácticas e instituciones que persisten a lo largo del tiempo lo hacen porque cumplen una función $x$ de mejor modo que otras, o son más eficientes, etc., y de ese modo son "naturalmente" (i.e., inintencionadamente) seleccionadas.

¿En cuál categoría cae la narración del surgimiento del Estado que ofrece Nozick? Prima facie pareciera que bajo la categoría de las explicaciones agregativas, pues la suya parece únicamente ofrecer una explicación de la emergencia del Estado a partir de un conjunto de acciones individuales encaminadas a un fin distinto de dicho surgimiento. Además, como advierte Ullmann-Margalit, bajo ciertas restricciones, una explicación agregativa de mano invisible puede ser hipotética, esto es, fructífera como explicación aun cuando no pueda verificarse que el proceso o la institución cuyo origen se intenta explicar efectivamente ha tenido lugar mediante el proceso inintencionado que ella describe (Ullmann-Margalit, 1978: 276 y ss.). No obstante, la explicación del surgimiento del Estado de Nozick no puede ser una explicación agregativa, por dos motivos. Si se entiende que los procesos agregativos que dan lugar de modo inintencionado a 
prácticas o instituciones son, como dice Nozick, procesos de equilibrio, ${ }_{11}^{11}$ entonces su explicación del surgimiento del Estado evidentemente no es una explicación de esta clase: ninguna explicación que culmine en el quiebre del equilibrio homeostático del mercado mediante la aparición de un monopolio puede provenir de una genuina explicación agregativa. ${ }^{12}$

La segunda razón de por qué la explicación de mano invisible de Nozick no puede ser una explicación agregativa radica en que dicha explicación pretende un alcance normativo (en la medida en que describe un proceso que culmina en la aparición lícita del Estado ultramínimo). Pero por eso -y en el entendido de que las explicaciones funcionales-evolutivas pueden tener un alcance normativo- podría llegar a creerse que la explicación ofrecida por Nozick para explicar el surgimiento del Estado es una explicación funcional-evolutiva. No obstante, dicha explicación tampoco se deja subsumir en esta última categoría. Primero, porque un argumento de mano invisible funcional-evolutivo no puede tener un carácter puramente hipotético ni valer de modo puramente hipotético. Y no lo puede tener por la misma razón por la cual no puede decirse de una especie que no existe que es todo un éxito adaptativo. Una explicación funcional-evolutiva de mano invisible puramente hipotética es un oxímoron. Para que tenga sentido esgrimir la explicación funcional-evolutiva como argumento en favor de una institución o práctica social, esa institución o práctica debe haber sido exitosa y haber subsistido después de un proceso de selección "natural". En una explicación funcional-evolutiva puramente hipotética hay encerrada una paradoja, cuando no una contradicción.

Pero además, la explicación ofrecida en ASU no puede ser funcional-evolutiva porque Nozick mismo es reticente a aceptar las razones puramente evolutivas como criterio de selección de las instituciones sociales: su corrección dependerá, para Nozick, del "test selectivo que haya pasado y del criterio incorporado por este test" (Nozick, 1995: 179). Y obviamente, el criterio que refleja el test no puede, por su parte, ser a su vez resultado del mismo proceso de mano invisible cuya corrección hay que testear.

Pero si la explicación de mano invisible presentada por Nozick en ASU no cae bajo ninguna de las dos categorías antes indicadas, ¿cómo se la debe entender? Y -más importante aún- ¿de dónde obtiene su fuerza normativa? El único modo coherente de interpretar la explicación y evitar las paradojas y dificultades recién apuntadas es entender que su fuerza normativa no viene dada por consideraciones "evolucionistas" sino, en definitiva, por el particular "filtro" que informa y hace posible todo el proceso de mano invisible descrito por Nozick: el universo lockeano (i.e., estado de naturaleza lockeano, agentes lockeanos y derechos naturales lockeanos). Es decir, Nozick describe un proceso que opera sobre la base de un filtro que no es, a su vez, producto de un proceso de mano invisible y que, por el contrario, hace posible el surgimiento del orden ulterior descrito en ASU. Una vez que se asume el filtro, lo demás (i.e., el Estado

11 Entendiendo, por tanto, además que hay una correspondencia biunívoca entre la clasificación de Nozick y la clasificación de Ullmann-Margalit de los procesos de mano invisible.

12 Agradezco al profesor Alejandro G. Vigo por esta observación. 
ultramínimo) viene por añadidura. En consecuencia, debe entenderse que el argumento de Nozick a favor del Estado es, en realidad, una explicación de mano invisible sui generis a la que podemos bautizar como explicación funcional-normativa. La explicación puede ser denominada así porque el filtro contiene ciertas premisas normativas que excluyen de antemano un sinnúmero de acciones (por ejemplo, las predatorias) y un tipo particular de agente (por ejemplo, el maximizador hobbesiano), de modo que todo el proceso subsiguiente informado por dicho filtro se desarrolla dentro de ciertos cauces que, efectivamente, hacen que el resultado final (o, más precisamente, gran parte de él) sea lícito (según las condiciones establecidas en el mismo filtro) y emerja de modo inintencionado.

En consecuencia, la fuerza probatoria de toda la narración dependerá de la verdad o falsedad de las premisas normativas incluidas en el filtro inicial y que permiten que la "explicación" devenga en un argumento en favor del Estado (ultra)mínimo. Por consiguiente, la dificultad principal a que debe hacer frente la explicación de Nozick es la de justificar el punto de partida (el universo lockeano), pues de lo contrario siempre se le podrá acusar de estipular un filtro ad hoc para obtener un determinado resultado querido de antemano. Toda la justificación que Nozick ofrece para dicho filtro es que un universo lockeano es el punto de partida que más favorece a un anarquista individualista (1988: 17-18). Si bien es cierto que el propósito primario de la primera parte del libro es refutar al anarquista individualista y demostrar, por consiguiente, la licitud del Estado a partir de las mismas premisas que dicho individualista adopta, para el no anarquista esa justificación es claramente insuficiente. Sin necesidad de entrar ahora en el problema de cuál es el fundamento último sobre el que descansa $A S U,{ }_{1}^{13}$ puede al menos adelantarse un argumento intuitivamente atractivo en favor de la asunción de un universo lockeano como punto de partida del razonamiento moral y político (y con ello, del filtro elegido por Nozick en favor de todo su argumento de mano invisible): las condiciones descritas por Locke reflejan las condiciones de la agencia racional en general $y$, en consecuencia, es necesario suponer y adherir a dichas condiciones a la hora de emprender cualquier intento de justificación moral y político de las prácticas y las instituciones sociales. ${ }^{14}$

Si la interpretación ofrecida aquí del "argumento" a favor del Estado elaborado por Nozick es correcta, entonces parece necesario admitir: 1) que la explicación de mano invisible tiene por finalidad llevar los acontecimientos al punto crítico en que la prohibición al independiente se vuelve factible. Por ello, aunque podría concederse que en la narración de Nozick la función que desempeña la explicación de mano invisible es fundamental para precipitar la eclosión del Estado, lo cierto es que desde el punto de vista normativo es superflua: ella no aporta, sino que simplemente refleja las premisas normativas incorporadas en el filtro (derechos naturales lockeanos) y no ofrece, en rigor, argumentos para la instauración (o emergencia) del Estado propiamente tal; 2) el argumento de Nozick a favor del Estado tiene más plausibilidad 
de lo que parece a primera vista, pero no porque consista en una explicación de mano invisible, sino por las premisas normativas (el "filtro inicial") de las que parte; 3) que la explicación de mano invisible a que apela Nozick en ASU no parece ser, en estricto rigor, una explicación fundamental del campo político, pues se monta sobre premisas normativas como los derechos naturales lockeanos. Nozick, claro está, podría replicar aún que él entiende "político" únicamente en el sentido de "preEstatal" (1988: 21). Pero probablemente con esa respuesta solo se estaría escamoteando el problema, pues las restricciones morales lockeanas contienen in nuce todos los principios y reglas que regulan el campo político lockeano. Para que el argumento fuera realmente "fundamental", debería explicar cómo de medios o elementos no morales, surgen las categorías morales fundamentales (que a su turno informarán las categorías políticas lockeanas fundamentales). Esta objeción, sin embargo, no tiene por qué echar por tierra el argumento. Sí supone renunciar a lo que, cree Nozick, es una ventaja comparativa frente a otro tipo de explicaciones.

\section{RIESGO Y COMPENSACIÓN: LÍMITES DEL ARGUMENTO DE MANO INVISIBLE}

Seguramente se podría conceder sin mayores problemas que la explicación de Nozick prueba que en un estado original lockeano podría lícitamente surgir a través de un proceso de mano invisible un Estado ultramínimo. Pero ¿y el tránsito al Estado mínimo?

El momento crítico en la narración del surgimiento del Estado es aquel en que la agencia que tiene el monopolio de facto del uso de la fuerza prohíbe al independiente ejercer por sí mismo su derecho al castigo apelando para ello al principio que autoriza a impedir a otros la realización de acciones que crean riesgos a terceros a cambio de una compensación. En este caso, el riesgo viene dado por el hecho de que el procedimiento aplicado por el independiente no es confiable y, en consecuencia, atenta contra el derecho natural al debido proceso (Nozick, 1988: 107 y ss.).

Obviamente, este giro en el decurso del argumento suscita varios problemas e interrogantes. ${ }^{15}$ Por de pronto, no solo la agencia tiene derecho a prohibir al independiente que aplique su procedimiento. El independiente tiene un derecho equivalente respecto de la agencia y por eso pregunta retóricamente Rothbard que qué pasa con el derecho del independiente "a bloquear las actividades temerarias de la agencia dominante" (1995: 322). Nozick afirma que, como la agencia monopólica es la única que tiene el poder de hacer cumplir su prohibición al independiente -y no al revés-, se aplicará de hecho su procedimiento (es decir, el de la agencia) y no el del independiente. Pero el hecho de que la agencia sea la única que cuente con el poder necesario para hacer efectiva su prohibición no es un motivo suficiente para autorizarla, además, a hacerlo. Las dificultades que suscita la

15 Por ejemplo: ¿Qué ocurriría con el independiente que empleara el mismo procedimiento que emplea la agencia? Porque, como bien observa Simmons, Nozick solo puede argumentar en contra de las "aplicaciones privadas y peligrosas de justicia" (2006: 136). 
prohibición no pueden ser resueltas diciendo que la agencia tiene el derecho a imponer la prohibición porque tiene una posición privilegiada -incluso monopólica-en el mercado, aun cuando la haya alcanzado compitiendo lealmente. El que la agencia haya alcanzado esa posición limpiamente y tenga, por tanto, "derecho" a su posición monopólica es una cuestión distinta de si, además, está autorizada a prohibir algunos de los procedimientos empleados por los independientes. Por ello, para que el argumento funcione, Nozick necesita que la agencia tenga el derecho a prohibir al independiente la aplicación de su procedimiento. Pero tal derecho a prohibir los procedimientos riesgosos solo funciona, como explica Miller (2002: 23), si asumimos que existe un procedimiento que es objetivamente mejor que otros y que, además, la agencia emplea ese procedimiento y no uno peor. Por tanto, si Nozick quiere que el argumento en favor del Estado funcione, tiene que establecer el conjunto de condiciones necesarias para discriminar entre el ejercicio lícito e ilícito de la justicia privada en estado de naturaleza.

Pero ¿cómo resolver el problema de qué procedimiento es mejor en estado de naturaleza? Suponiendo que existen presumiblemente muchos procedimientos igualmente razonables ¿apelando a qué proceso de arbitraje puede zanjarse una disputa como esta? Sin contar con que este problema tiene un carácter recursivo ${ }^{16}$, lo que necesitaría además Nozick es dar con un procedimiento que fuere inequívocamente mejor que los otros y que ningún privado -con excepción de la misma agencia- pudiere estar en condiciones de instaurar. Pero como no es posible establecer a priori qué procedimiento es mejor o preferible a otro y, como además, las condiciones para producir la prueba que Nozick necesita -i.e., que ese procedimiento solo sea factible de aplicar a la agencia dominante y no a cualquier independiente- no parecen tampoco posibles de satisfacer, el anarquista individualista siempre podrá decir que el intento acometido en la primera parte de ASU de probar la licitud del Estado a partir de las premisas y restricciones de un estado de naturaleza lockeano ha fracasado.

Adviértase, no obstante, que la dificultad para determinar el procedimiento adecuado en estado de naturaleza se vuelve también en contra del anarquista individualista. La razón por la que en el estado de naturaleza no existen criterios últimos que permiten discriminar entre procedimientos igualmente razonables, es que en dicho estado no existe una autoridad imparcial con competencia para instaurar uno de ellos, pues la razón por la que deba aplicarse un procedimiento en lugar de otro (igualmente razonable) descansa en último término en una decisión autoritativa y no en argumentos puramente morales. Dicho de otro modo, la necesidad de aplicar un procedimiento más que otro no puede zanjarse a partir de consideraciones puramente iusnaturalistas como el mismo Nozick parece avizorar cuando dice que no parece "haber una forma clara de entender cómo funcionaría el derecho de castigar en el estado de naturaleza" (1988: 142).

Las dificultades que suscita el ejercicio de la justicia privada permiten concluir, entonces, dos cosas. Primero, que el intento de Nozick de justificar el Estado sin apelar al contrato $\mathrm{u}$ otro medio explícito y visible de instauración de una autoridad judicial es inviable; 
segundo, que la victoria del anarquista individualista contra Nozick es una victoria pírrica, pues la imposibilidad de determinar unívocamente en estado de naturaleza cuál de entre distintos procedimientos igualmente razonables es mejor es también una razón para desechar el anarquismo individualista: de la constatación de esta dificultad procesal no se sigue otra cosa que la necesidad de instaurar una autoridad común dotada de poderes jurisdiccionales, pues salvo casos disparatados o manifiestamente inicuos, la preferencia de un procedimiento sobre otro no se sigue de razones a priori, sino que de convenciones sociales.

\section{PRINCIPIO DE COMPENSACIÓN, “CLÁUSULAS LOCKEANAS” Y ESTADO MÍNIMO}

Nozick parece creer que puede sencillamente eludir las dificultades que suscita el ejercicio privado de la justicia por medio de lo que él denomina principio de compensación. La idea que subyace al principio es que la transgresión de un derecho es lícita si es que va acompañada de una compensación suficiente. ${ }^{17}$ Conforme al principio, entonces, una compensación suficiente redime a un acto de su ilicitud, al menos bajo ciertas condiciones. Nozick intenta exponer esas condiciones de aplicación del principio de compensación en lo que denomina el principio epistémico de traspaso de límites (PETL). Conforme a este principio general,

si alguien sabe que hacer el acto $A$ viola los derechos de $Q$, a menos que la condición $C$ sea satisfecha, no puede hacer $A$ si no ha determinado que $C$ es satisfecha encontrándose en la mejor posición factible para hacerlo (1988: 111).

En conformidad con el PETL, entonces, la agencia podría lícitamente prohibir al independiente el ejercicio de la justicia privada aun cuando no sea posible establecer de modo inequívoco cuál de los dos procedimientos empleados es el mejor, si es del independiente o el de la misma agencia. Por tanto, la idea de Nozick es que la arbitrariedad que comporta la prohibición al independiente es inocua si es que va a acompañada de una compensación suficiente en su favor. Más específicamente, que la arbitrariedad que supone ejercer funciones jurisdiccionales sin tener autoridad para ello resulta inocua si va acompañada de una compensación suficiente. ${ }^{18}$

El PETL, bajo el cual queda subsumido el principio de compensación, completa así el argumento de Nozick a favor del Estado. Pues bien ¿cómo evaluar el argumento? ¿prueba lo que intenta probar?

17 “ ¿E]stá prohibido a los otros realizar acciones que traspasen los límites o invadan el área circunscrita [por los derechos de una persona]? ¿Les está permitido realizar tales acciones siempre que compensen a la persona cuyo límite han rebasado?" (1988: 65).

18 "Algo compensa completamente a una persona por una pérdida si y solo si no está peor de lo que estaría de otra manera [...] (En la terminología de los economistas, algo compensa a $X$ por los actos de $Y$ si al recibirlo lleva a $X$ tan alto en una curva de indiferencia como estaría sin esta compensación y $Y$ no actuado)" (Nozick, 1988: 65-66). 
Dado que el argumento de Nozick pretende demostrar que hay un escenario hipotético en que el surgimiento del Estado podría ser lícito según las mismas premisas del anarquista individualista, para que el argumento en favor del Estado ofrecido en ASU sea exitoso basta, en rigor, con que el PETL y el principio de compensación sean compatibles con las premisas y reglas de un estado de naturaleza lockeano.

Existe una poderosa razón para sostener la concordancia entre el principio de compensación y las premisas de un estado de naturaleza lockeano: en su teoría de la propiedad el propio Locke admite tácitamente la lógica que sigue el PETL.

Como se sabe, Locke sostiene contra Filmer que originariamente los bienes son comunes. Esa comunidad originaria plantea un problema a la hora de intentar justificar el tránsito de la propiedad común a la propiedad privada, pues por ella toda apropiación privada constituye, al menos prima facie, una transgresión de los derechos comunes de propiedad preexistentes de todos los demás. ${ }^{19} \mathrm{Y}$ como Locke no cree que el contrato constituya una herramienta idónea para superar esta dificultad (pues considera del todo improbable que los primeros hombres hubieran podido convenir en una división concreta de bienes), se ve en la necesidad de idear un modo originario no contractual de apropiación privada que no constituya, sin embargo, un robo. ${ }^{20}$ La célebre solución de Locke es apelar al trabajo más el cumplimiento de ciertas condiciones conocidas como las cláusulas lockeanas. Por consiguiente, las cláusulas necesitan ser introducidas porque sin condiciones como las que en ellas se establecen, las apropiaciones privadas de bienes originariamente comunes dañan los derechos preexistentes de todos los demás. Las cláusulas, en consecuencia, salvan los derechos de terceros convirtiendo en lícito un acto que de otra manera sería ilícito.

Es difícil resistir la tentación de trazar aquí un paralelo entre la argumentación de Locke y la de Nozick, pues la situación del primer adquirente es para Locke análoga a la situación en que se encuentra la agencia respecto del independiente: ambos necesitan realizar un acto que transgrede los derechos de otros, de modo que ambos tienen que hallar las condiciones descritas en el PETL que permiten prescindir lícitamente del consentimiento de esos otros. Las cláusulas lockenas expresan esas condiciones para el caso de la apropiación privada y el principio de compensación para el caso de la proscripción de la justicia privada. Por ello, si considerando todo lo anterior uno se preguntara si el principio de compensación respeta las condiciones y restricciones de un universo lockeano, la respuesta que debiera darse es que, pese a las apariencias, sí lo hace, pues en dicho universo el PETL resulta ser un principio general válido y socorrido. Esta concordancia ha sido pasada por alto por los libertarios y por los anarcocapitalistas que rechazan la viabilidad del argumento de Nozick a favor del Estado. Sin embargo, en virtud de dicha compatibilidad debieran sentirse más inclinados a admitir la plausibilidad que el argumento de Nozick tiene bajo los supuestos a que ellos mismos adhieren. 


\section{CONCLUSIONES}

El éxito del argumento de Nozick a favor del Estado depende de la viabilidad del principio de compensación y del PETL. Por ello, y con vistas a la refutación del anarquismo individualista, resulta esencial comprobar la compatibilidad de tales principios con las reglas y premisas de un estado de naturaleza lockeano. Como además es necesario tener en cuenta que el principio de compensación y, en términos más generales, el PETL permiten prescindir lícitamente del consentimiento de aquellos a que alcanzan los efectos de los actos que uno realiza -eludir lícitamente el consentimiento de otros a la hora de adquirir una propiedad; eludir el consentimiento de otros a la hora de instaurar un Estado, según el caso-seguramente resulta cierto afirmar que una sociedad libertaria necesita de ellos para poder funcionar. El caso de la apropiación de bienes y del desarrollo de actividades económicas son buenos ejemplos de ello, pues difícilmente se podrá recabar el consentimiento de todos los afectados cada vez que se adquiere un bien o se emprende alguna actividad que produce algún tipo de externalidad negativa. $\mathrm{Al}$ apropiarme, por ejemplo, de una parcela de tierra, necesariamente reduzco el acervo total de tierra disponible para todos los demás ¿Significa eso entonces que no puedo hacerlo de no contar con el consentimiento de todos ellos? ¿O que puedo bajo ciertas condiciones? (y la necesidad de cumplir con ciertas condiciones explica que una teoría libertaria de la propiedad deba incluir cláusulas como las descritas por Locke) Y si quiero desarrollar una actividad que contamina la atmósfera ¿necesito el consentimiento de alguien? ¿de quién específicamente? ¿O puedo hacerlo directamente mientras deje incólumes los derechos de otros? El PETL no es una herramienta ad hoc introducida por Nozick para completar el argumento a favor del Estado. Por el contrario, Nozick se ve en la necesidad de formular el PETL al hilo de una reflexión más general acerca de lo que en una sociedad libertaria los individuos pueden lícitamente hacerse de modo directo o indirecto sin prestarse el consentimiento mutuo. Por ello, el PETL es un sucedáneo necesario -e insustituible- del contrato en un universo lockeano, sucedáneo que constituye una prolongación del principio liberal que establece que cada uno tiene derecho a obrar como quiera mientras con ello no perjudique los derechos de otros. Por tal motivo, el PETL es el único modo de legitimar sine contractu ciertas actividades que no podemos dejar de realizar y que afectan a terceros cuya autorización unánime no podemos obtener. La originalidad de Nozick consiste, entre otras cosas, en extender el PETL a la instauración del Estado. Si una sociedad libertaria (anarquista o no) no puede funcionar sin un principio como el PETL, entonces no parece haber una razón para desechar de antemano tal extensión. Por ello, y en vista de la importancia que dicho principio tiene para una sociedad libertaria, los libertarios y anarquistas de inspiración lockeana harían bien en tomarse el argumento de Nozick en serio: según el PETL bien podría ocurrir que el Estado surgiera lícitamente en un estado de naturaleza lockeano. Y a Nozick le basta con esa posibilidad. 


\section{REFERENCIAS}

Barnett, Randy E. 1977. “Whither Anarchy? Has Robert Nozick justified the State?" Journal of Libertarian Studies 1 (1): 15-21.

Dworkin, Ronald. 1984. Los derechos en serio. Traducción de Marta Guastavino. Barcelona: Editorial Ariel.

Friedman, Mark D. 2011. Nozick's Libertarian Project. An Elaboration and Defense. London: Continuum Studies in Political Philosophy.

Gaus, Gerald. 2011. "Explanation, Justification, and Emergent Properties: An Essay on Nozickian Metatheory". En The Cambridge Companion to Nozick's Anarchy, State, and Utopia, editado por Ralf M. Baader y John Meadcroft, 116-142. New York: Cambridge University Press.

Hempel, Carl G. 2005. La explicación científica. Estudios sobre filosofía de la ciencia. Traducción de M. Frassineti de Gallo, Néstor Míguez e Irma Ruíz Aused. Barcelona: Paidós.

Holmes, Robert L. 1981. "Nozick on Anarchism", En Reading Nozick. Essays on Anarchy, State and Utopia, 57-67. Oxford: Basil Blackwell.

Hoppe, Hans-Herman. 1987. Eigentum, Anarchie und Staat. Studien zur Theorie des Kapitalismus. Opladen: Westdeutscher Verlag.

Hume, David. 1994. Ensayos políticos. Traducción de Gómez, César Armando. Madrid: editorial Tecnos.

Mack, Eric. 1981. "Nozick on Unproductivity: The Unintended Consequences”. En Reading Nozick. Essays on Anarchy, State and Utopia, editado por Jeffrey Paul, 169-190. Oxford: Basil Blackwell.

2011, "Nozickian Arguments for the More-than-minimal State". En The Cambridge Companion to Nozick's Anarchy, State, and Utopia, editado por Ralf M. Baader y John Meadcroft, 89-115. New York: Cambridge University Press.

Marshall, Peter H. 2008. Demanding the Impossible. A History of Anarchism. London, New York, Toronto, Sydney: Harper Perennial.

Miller, David. 2002. "The Justification of Political Authority". En Robert Nozick, editado por David Schmitdtz, 10-33. New York: Cambridge University Press.

Murphy, Jeffrie G. 1969. "A Paradox in Locke XE "Locke" 's Theory of Natural Rights". Dialogue 8: 256-271.

Nagel, Thomas. 1981. "Libertarianism Without Foundations". En Reading Nozick. Essays on Anarchy, State and Utopia, editado por Jeffrey Paul, 191-205. Oxford: Basil Blackwell.

Nozick, Robert. 1974. Anarchy, State, and Utopia. Oxford: Basic Books. 1988. Anarquía, Estado y utopía. Traducción de Rolando Tamayo. Fondo de Cultura Económica. 1994. "Invisible-Hand Explanations". The American Economic Review 84 (2): 314-318. 1995. La naturaleza de la racionalidad. Traducción de Antoni Domènech. Barcelona: Paidos.

Paul, Jeffrey. 1981. "The Withering of Nozick's Derivation of the Minimal State". En Reading Nozick. Essays on Anarchy, State and Utopia, editado por Jeffrey Paul, 68-76. Oxford: Basil Blackwell

Paul Wolff, Robert. 1981. "Robert Nozick's Derivation of the Minimal State". En Reading Nozick. Essays on Anarchy, State and Utopia, editado por Jeffrey Paul, 77-14. Oxford: Basil Blackwell.

Roark, Eric. 2007. “Nozick's Failed Defense of the Just State". Journal of Libertarian Studies 21 (1): 5-39.

Rothbard, Murray N. 1995. Laética de la libertad. Traducción de Marciano Villanueva Salas. Madrid: Unión editorial. Simmons, A. John. 2005. “Consent Theory for Libertarians”. En Natural Rights Liberalism from Locke to Nozick, editado por Elle Franken Paul, Fred. D. Miller Jr. y Jeffrey Paul, 330-356. Cambridge: Cambridge University Press. Sreenivasan, Gopal. 1995. The Limits of Lockean Rights in Property. New York-Oxford: Oxford University Press. Tully, James, A. 1980. Discourse on Property. John Locke and his Adversaries. Cambridge: Cambridge University Press. Ullmann-Margalit, Edna. 1978. "InvisibleHand Explanations". Synthese 39: 263-291.

Wolff, Jonathan. 1991. Robert Nozick. Property, Justice and the Minimal State. Cambridge: Polity Press.

Young, Fredric C. 1986. "Nozick and the Individualist Anarchist". Journal of Libertarian Studies 8 (1): 43-49.

Felipe Schwember Augier es Profesor del Centro de Investigación en Teoría Social y Política de la Escuela de Gobierno, Universidad Adolfo Ibáñez.

E-mail: felipe.schwember@uai.cl 